Cognitive neuropsychological analysis of differential reading and spelling disorder mechanisms in a patient with aphasia

$$
\text { Kosei Hashimoto }^{1,2} \text {, Akira Uno }{ }^{1}
$$

1. Comprehensive Human Sciences, University of Tsukuba

2. Department of rehabilitation, Kumamoto General Hospital 


\title{
Cognitive neuropsychological analysis of differential reading and spelling disorder mechanisms in a patient with aphasia
}

\author{
Kosei Hashimoto, Akira Uno
}

\begin{abstract}
The purpose of this study was to determine if differential reading and spelling mechanisms were involved in a Japanese patient with aphasia. In our case, the patient scored low on all of the administered reading tasks, suggesting that both the reading lexical and non-lexical routes were impaired. In contrast, his writing-to-dictation score for Kana non-words was high, suggesting that the spelling non-lexical route was intact. However, the patient scored low on a writing-to-dictation task comprised of high familiarity Kanji words. The spelling lexical route was thought to be impaired. Therefore, the mechanism(s) involved in reading and spelling may differ in this case.
\end{abstract}

Key words: reading, spelling, aphasia, Japanese, cognitive neuropsychology 


\section{Introduction}

Acquired dyslexia and dysgraphia are traditionally divided into several types: pure alexia (Déjerine, 1892), pure agraphia (Exner, 1881), and alexia with agraphia (Déjerine, 1891). These classifications were determined using descriptive neuropsychological methods that investigated the underlying relationship between symptoms and specific brain areas. In contrast to neuropsychological descriptive analysis, cognitive neuropsychological methods identified mechanisms of dysfunction in accordance with deficits in processing routes or levels within the information processing model. Reading and spelling impairments were divided into subclasses based on the cognitive neuropsychological paradigm (Benson, 1996; Roeltgen, 2003). For example, surface dyslexia/dysgraphia is characterized by deficits in the lexical processing route (Barry, 1988; Baxter \& Warrington, 1987; Marshall \& Newcombe, 1973; McCarthy \& Warrington, 1986; Warrington \& McCarthy, 1987; Weekes, Davies, Parris, \& Robinson, 2003), whereas deep or phonological dyslexia/dysgraphia is characterized by deficits in the non-lexical processing route (Baxter, \& Warrington, 1985; Beauvois, \& Derouesné, 1979; Bub, \& Kertesz, 1982; Cipolotti, Bird, Glasspool, \& Shallice, 2004; Jones, 1985; Marshall, \& Newcombe, 1966; Roeltgen, Sevush, \& Heilman, 1983; Sasanuma, Ito, Patterson, \& Ito, 1996; Shallice, 1981). These categorical syndromes have been studied based on single case reports of individuals. Surface dyslexia/dysgraphia results from damage to the lexical route for reading/spelling. This form of dyslexia/dysgraphia is characterized by difficulties in reading/spelling irregular words compared to regular words and pronounceable non-words. In contrast, phonological dyslexia/dysgraphia results from damage to the non-lexical route for reading/spelling. In this form of dyslexia/dysgraphia, while the reading/spelling of known words is preserved, that of non-words is impaired. 
Although deep dyslexia/dysgraphia shares similar characteristics to those of phonological dyslexia/dysgraphia, semantic errors are observed only in deep dyslexia/dysgraphia (Marshall \& Newcombe, 1966, 1973; Plaut \& Shallice, 1993; Bub \& Kertesz, 1982a).

Studies analyzing both reading and spelling impairments in a single case using the cognitive neuropsychological method are rare (Beauvois \& Dérouesné, 1981; Roeltgen \& Heilman, 1984; Tainturier \& Caramazza, 1994). Beauvois \& Dérouesné (1981) reported on a patient with aphasia who displayed both phonological dyslexia and surface dysgraphia. Their findings suggested that the mechanisms of dysfunction may have clearly differed between reading and spelling in that patient. In addition, Roeltgen \& Heilman (1984) reported four cases each of phonological dysgraphia and surface dysgraphia (referred to as "lexical agraphia" in their article). In one of the cases with surface dysgraphia, spelling of non-words was impaired; however, in the current case, the reading of non-words was intact. In the case reported here, the mechanism of dysfunction for reading and spelling impairment may be different, resembling the case reported by Beauvois \& Dérouesné.

In this study, we analyzed reading and spelling impairments in a Japanese patient with aphasia. There are two kinds of orthographic systems used in Japanese: syllabic Kana and logographic Kanji. Character-sound correspondence in Japanese Kanji characters are completely different from Kana in several regards. First, a Kana character usually maps to a single mora of spoken Japanese, whereas Kanji characters do not reliably map to any specific phonological size of a Kanji character, which generally contains from one to three morae. Second, although almost all Kana characters have a single pronunciation that does not vary across different words, the majority of Kanji characters have two or more different pronunciations as determined by the intra-word context. Third, Kanji characters are visually complex compared with Kana characters (Fusimi, Ijuin, 
Patterson, \& Tatsumi, 1999, Morton \& Sasanuma, 1984). In the discussion, we analyzed the relationship between script type (Kanji or Kana) and dysfunction mechanisms in our case, based on the dual route cascaded (DRC) model. In addition, we discussed the patient's dysfunction in relation to localized cerebral lesions. Furthermore, we attempted to compare our case with the case reported by Beauvois \& Dérouesné.

\section{Case Report}

KH was a 79-year-old, right-handed man who worked as a farmer and exhibited speech difficulties following a cerebral infarction. There was no history of cerebrovascular disease prior to the event. Clinical examinations revealed right homonymous hemianopia, mild anomia, and mild attention and memory impairments. On the other hand, no apraxia or agnosia was present. His past medical history included an irregular pulse and cataract. To regulate his heartbeat, he underwent surgery to insert a pacemaker. The patient also underwent cataract surgery to restore his vision. The patient's ability to engage in typical daily conversation was almost normal despite his mild difficulty with word recall. A head computed tomography (CT) scan acquired 2 days after onset revealed low-density areas in the lower left temporal lobe extending to the left occipital lobe, as well as a small infarction in the parietal lobe (Figure 1). The CT images indicated that both the posterior cerebral artery and the posterior branches of the middle cerebral artery were simultaneously damaged. The patient underwent detailed evaluations of his cognitive and language abilities, including neuropsychological tests and speech-language assessments. To examine our case's visual perception abilities, we administered the Visual Perception Test for Agnosia (VPTA; Japan Society for Higher Brain Dysfunction Test Committee, 2003b), a commonly used test in Japan. Our results 
showed that the visual perception abilities of our case were within the normal range. To evaluate his language ability, we conducted the Japanese Standard Language Test for Aphasia (SLTA; Japan Society for Higher Brain Dysfunction Test Committee, 2003a), which is the most commonly used standardized test battery in Japan. In addition, several Sophia Analysis of Language in Aphasia (SALA; Jochi university SALA project team, 2004) tasks were used to examine his reading and writing abilities.

\section{Results}

The SLTA results are shown in Table 1. The patient scored a 0 out of 5 in Kanji and a 5 out of 5 in Kana on the written naming task. On the Kanji and Kana writing-to-dictation tasks, he scored a 1 out of 5 and a 5 out of 5 , respectively. The same tendency was observed between Kanji and Kana in both the written naming task and the writing-to-dictation task. Conversely, his reading aloud scores in both Kanji and Kana were 1 out of 5 . The patient's auditory comprehension and repetition abilities were within the normal ranges. However, his oral naming and reading comprehension scores were low.

In order to analyze his reading/writing disorders more deeply, we administered several tasks using the SALA test battery (the Japanese version of the Psycholinguistic Assessments of Language Processing in Aphasia [PALPA; Kay, Lesser, \& Coltheart, 1992]). To examine the underlying mechanism involved in his reading/writing impairments, we administered four tasks: a character/pseudo-character discrimination task, an orthographic lexical decision task, a word/non-word reading aloud task, and a word/non-word spelling task.

In the character/pseudo-character discrimination task, the patient was required to 
determine whether the character presented was real or not. Stimuli were comprised of 28 real Kanji (e.g., 朝) and 28 pseudo-Kanji characters (e.g., ). The patient scored within the normal range on the character/pseudo-character discrimination task, with 53 out of 56 correct answers. The orthographic lexical decision task stimuli were comprised of 60 real Kanji words and 60 non-words, and 32 real Kana words and 32 non-words. The patient answered correctly 21 out of 40 times on the Kanji portion and 0 out of 12 times on the Kana portion of the lexical decision task. The Kanji orthographic lexical decision task score was significantly lower than that of the character/pseudo-character discrimination $\operatorname{task}\left[\chi^{2}(1)=21.13, \mathrm{p}<.01\right]$

For the reading aloud task, we used high familiarity Kanji/Kana words and Kana non-words as stimuli. High familiarity word stimuli were comprised of 30 Kanji and 60 Kana words (30 Hiragana words and 30 Katakana words). In addition, we used 56 Kana non-word stimuli for the reading task. In the high familiarity word reading aloud task, the patient scored low on all scripts [correct answers: Kanji words, 2 out of 30; Kana words: 4 out of 60 (Hiragana words, 2 out of 30; Katakana words, 2 out of 30)]. The patient could not read aloud in the Kana non-word reading task; his score was 0 out of $28 . \quad$ In the high familiarity reading task with Kana words, two error response patterns were observed: no responses, 54 out of 56; and only one syllable responses, 2 out of 56 (e.g., たこ[tako] 'octopus' $\rightarrow[\mathrm{sa} \ldots])$. In the high familiarity Kanji word reading task, he reported that he could understand the meaning of 5 out of 27 words, which he was not able to read aloud. Further, character-by-character reading responses were not observed in all reading tasks.

The writing-to-dictation task was comprised of high familiarity Kanji/Kana words and Kana non-words; the same stimuli were used in this task as were used in the reading aloud task. When we asked the patient to dictate the stimulus word, he repeated the word 
correctly before he started to write it down. On the high familiarity spelling task, the patient answered correctly 54 out of 60 times for the Kana words (Hiragana words, 28 out of 30; Katakana words, 26 out of 30), whereas he scored a 4 out of 30 on the Kanji words. His Kanji word score was significantly lower than that for Kana words $\left[\chi^{2}(1)=48.01, p\right.$ $<.01]$. The patient scored significantly higher on the high familiarity Kana word spelling task than on the Kana reading task (spelling, 54 out of 60 ; reading, 4 out of $60 ; \chi^{2}(1)=$ $80.12, \mathrm{p}<.01)$. He scored a 47 out of 56 on the non-word spelling task, which was similar to his high familiarity Kana word score. No significant difference was found between his spelling scores for Kana words and non-words. Figure 2 shows the results of the reading and spelling tasks.

In the writing-to-dictation task with high familiarity Kanji words, the patient made various errors: no response, 15 out of 26; responses with only one character written down, 3 out of 26 (e.g., 牛乳[giju:nju:]'milk' $\rightarrow$ 乳); response with a part of a character, 1 out of 26 (e.g., 電話[dẽẽwa]'phone' $\rightarrow$ ॠ), substitution with a character that was phonologically similar in Kanji, 1 of 26 (e.g., 水着[mizugi]'swimwear' $\rightarrow$ 水気[mizuki]); substitution with an unrelated Kanji character, 1 out of 26 (e.g., 紅茶[ko:tfa]’tea' $\rightarrow$ 近後); substitution with a pseudo-Kanji character, 1 out of 26 (e.g., 馬[uma]'horse' $\rightarrow$ 宛); response with Kana characters, 1 of 26 (e.g., 滝[taki]'waterfall' $\rightarrow$ [taki]).

In the writing-to-dictation task with high familiarity Kana words, all errors made were phonologically similar: character substitution errors, 5 out of 6 (e.g., じやがいも [dzagaimo]'potato' $\rightarrow$ ががい[gagaimo]); and omission of a long vowel, 1 out of 6 (e.g., ドーナツ[do:natsu]'doughnuts’ $\rightarrow$ ドナツ[donatsu]). In the Kana non-word writing-to-dictation task, the patient made errors that were similar to the error pattern observed with high familiarity Kana words. Specifically, all errors made in Kana 
non-words were phonologically similar: character substitution errors, 8 out of 9 (e.g., みつ

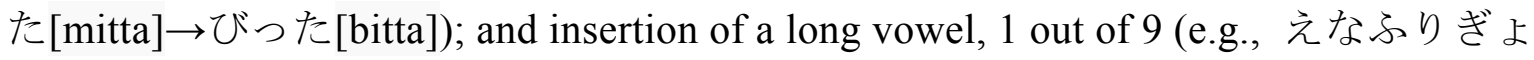

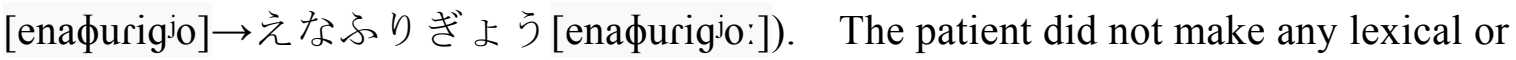
semantic errors on the writing-to-dictation tasks for either Kana words or non-words. Further, character-by-character writing responses were consistently observed in both tasks.

\section{Discussion}

The results of our patient's reading/writing tasks were as follows. The patient scored low on the reading aloud tasks consisting of high familiarity Kanji words, high familiarity Kana words, and Kana non-words. In contrast, his scores were high on the spelling tests for high familiarity Kana words and Kana non-words; his spelling test score was significantly lower for high familiarity Kanji words than that for high familiarity Kana words and non-words. Therefore, we analyzed the different mechanisms involved in reading and spelling dysfunction using the DRC model (Coltheart, Rastle, Perry, Langdon, \& Ziegler, 2001; Houghton \& Zorzi, 2003; Weekes et al., 2003).

First, we analyzed the reading dysfunction mechanism using the DRC model (Coltheart et al., 2001) (Figure 3). This model assumes that there are two processing routes for reading: the lexical route (Figure 3, left) and the non-lexical route (Figure 3, right). We used high familiarity words and non-words in order to analyze reading and spelling processing using the lexical and the non-lexical routes, respectively.

To read aloud, we must perceive character forms as visual stimuli before these characters are recognized as language symbols. In our case, visual perception was preserved, based his normal on VPTA score. In other words, visual feature units included in the DRC model were likely functioning appropriately. Further, the patient's normal 
score on the character/pseudo-character task indicated that his character units were intact.

Conversely, the patient only answered correctly $52 \%$ of the time on the orthographic lexical decision task, a percentage that was close to the number of correct answers that could be guessed by chance, indicating that the orthographic input lexicon was likely severely impaired. Therefore, the visual word input level analysis suggested that visual feature units and character units were likely preserved, whereas the orthographic input lexicon was impaired.

In the reading aloud tasks, the patient scored low on the high familiarity Kanji/Kana words, which suggested that one or more levels of the reading lexical route was/were impaired. The above analysis of visual word input levels suggested that the lexical route of the orthographic input lexicon was impaired. In addition, the phonological output lexicon may have also been impaired in our case, as he scored low on the oral naming task. Furthermore, his difficulty in reading Kana non-words aloud suggested that the non-lexical route (grapheme-phoneme conversion) was also impaired.

Second, we analyzed the spelling dysfunction mechanism using the DRC model of spelling; we modified the spelling model based on that of Houghton \& Zorzi (2003) and Weekes et al. (2003) (Figure 4). In this model, as well as in the DRC model of reading, high familiarity words are processed via the lexical route and non-words are processed via the non-lexical route. In our case, the spelling lexical route was likely impaired, as he scored low on the high familiarity Kanji word writing-to-dictation task. However, the non-lexical route of spelling was likely intact because the patient's percentage of correct answers on the writing-to-dictation task was high for Kana non-words. Further, we presented the patient with auditory stimuli to determine whether his low scores on the writing-to-dictation task were partially due to impaired phonological input. We found that 
the phonological input levels were likely intact in our patient because his auditory comprehension and repetition abilities were preserved.

Here we discussed Kana word processing in our case based on Japanese Kana processing characteristics associated with dysfunction mechanisms. We propose that the lexical route was impaired in our case; we determined this by using high familiarity Kana words, which are written via use of the lexical route. However, Japanese Kana words have a regular correspondence between characters and sounds; thus, native Japanese speakers can spell most Japanese Kana words using these correspondent rules. Our case could write Kana words via the preserved non-lexical route; therefore, he had a high score on the writing-to-dictation task for Kana words. Evidence for spelling Kana words using the non-lexical route is as follows: scores did not significantly differ between Kana words and non-words; parallel error patterns were observed between these two tasks; and character-by-character writing was consistently observed for both Kana word and non-word tasks.

In addition, we discuss KH's reading and spelling dysfunctions and their relationship with cerebral lesions. KH scored low on all of the administered reading tasks, a pattern similar to that observed in cases with pure dyslexia (dyslexia without dysgraphia). This pattern of reading impairment was thought to be caused by lesions in the occipital lobe, which is often damaged in patients with pure dyslexia (Damasio \& Damasio 1983). However, in contrast to typical pure dyslexia, character-by-character reading responses were not observed in our case. The mechanisms of pure dyslexia were described in several publications (Miozzo \& Caramaza, 1998), and included a disconnect between the visual process area and the language area (Déjerine, 1892, Geschwind, 1962), a correlation with deficits in visual perception (Farah \& Wallace, 1991), a deficit in recognizing letters 
(Arguin \& Bub, 1993), and a deficit in lexical orthographic representations themselves (Warrington \& Shallice, 1980) or faulty access to the orthographic lexicon (Patterson \& Kay, 1982). As previously mentioned, our case's reading difficulties may have been caused by a deficit in the orthographic input lexicon; this pattern was similar to the case of Warrington \& Shallice (1980). Further analysis suggested that many lesions do not entirely destroy the lexical pathway, such that partial sparing of the reading lexical pathways could account for some of the preserved reading abilities. In contrast to the lexical pathway, the reading non-lexical route may have been entirely destroyed because our patient could not read any Kana non-words. In contrast, the spelling non-lexical route was likely intact, as our case achieved a high score on Kana spelling tasks. The angular gyrus may be involved in the spelling non-lexical route because this area is damaged in patients with surface (lexical) dysgraphia (Roeltgen \& Heilman, 1984). Because these areas were preserved in $\mathrm{KH}$, the spelling non-lexical route was likely intact. On the other hand, it is known that Japanese Kanji and Kana disorders often dissociate in Japanese patients with brain damage. For instance, the posterior inferior temporal gyrus and the temporo-occipital area are known to cause selective dysgraphia in Kanji (Iwata, 1984, Soma, Sugishita, Kitamura, Maruyama, \& Imanaga, 1989, Sakurai, Sakai, Sakuta, \& Iwata, 1994, Sakurai, Mimura, \& Mannen, 2008). Our case suffered damage to the inferior temporal gyrus and the temporo-occipital area; therefore, we assumed that his Kanji spelling abilities were impaired as a result.

To summarize our case's reading/spelling dysfunction mechanisms, both lexical and non-lexical routes for reading were impaired, whereas only the lexical route was impaired for spelling. Therefore, the dysfunction mechanism(s) may differ between reading and spelling in this case. In addition to our case, a patient with differential mechanisms 
between reading and spelling disorders was previously reported (Beauvois \& Dérouesné, 1981). This case exhibited phonological dyslexia and surface dysgraphia, which led to the hypothesis that both the non-lexical route of reading and the lexical route of spelling were concurrently impaired. In our case, both the reading lexical and non-lexical routes were impaired, whereas the only the lexical route was impaired for spelling. In Table 2, we compare our case with Beauvois' case. Both cases had an intact non-lexical route for spelling, while the reading lexical route was impaired only in our case. Further, in both cases the non-lexical route for reading was impaired, whereas the non-lexical route for spelling was preserved. Therefore, these two routes are likely independent in both dysfunctional and normal cognitive mechanisms.

As we mentioned above, the reading lexical and non-lexical routes and the lexical route in spelling were impaired in KH. Qualitatively different mechanisms were involved in our case, as determined using cognitive neuropsychological methods. Both reading and spelling were impaired in $\mathrm{KH}$ and Beauvois' case; however, the reading and spelling dysfunction mechanisms differed. We identified different mechanisms underlying the reading and spelling disorders in our case compared with the case of Beauvois \& Dérouesné; therefore, reading and spelling dysfunction mechanisms might be variable in general. Moreover, our findings suggest that we should analyze reading disorders and spelling disorders separately using cognitive neuropsychological analysis. If reading and spelling dysfunction mechanisms differ, then language training methods should be changed.

\section{Acknowledgement}

We are grateful to Dr. Go Mizumoto for his helpful advice and comments. 


\section{References}

Arguin, M., \& Bub, D. N. (1993). Single-character processing in a case of pure alexia. Neuropsychologia, 31, 435-458.

Barry, C (1988). Modelling assembled spelling: Convergence of data from normal subjects and "surface"dysgraphia. Cortex 24(2), 339-346.

Baxter, D. M., Warrington, E. K. (1985). Categoryspecific phonological dysgraphia. Neuropsychologia 23, 653-666.

Baxter, D. M., Warrington, E. K. (1987). 'Transcoding sound to spelling: singleor multiple sound unit correspondences. Cortex 23, 11-28.

Beauvois, M. F., \& Dérouesné, J. (1981). Lexical or orthographic agraphia. Brain 104, $21-49$.

Beauvois, M. F., \& Derouesne, J. (1979). Phonological alexia: Three dissociations. Journal of Neurology, Neurosurgery and Psychiatry 42, 1115-1124.

Benson, D. F., \& Ardila, A. (1996). Aphasia. A clinical perspective. New York, NY: Oxford University Press.

Bub, D., \& Kertesz, A. (1982). Deep agraphia. Brain and Language 17, 146-165.

Cipolotti, L., Bird, C. M., Glasspool, D. W., Shallice T. (2004). The impact of deep dysgraphia on graphemic buffer disorders. Neurocase 10(6), 405-419.

Coltheart, M., Rastle, K., Perry, C., Langdon, R., \& Ziegler, J. (2001). DRC: A dual route cascaded model of visual word recognition and reading aloud. Psychological Review, 108, 204-256.

Damasio, A. R., \& Damasio, H. (1983). The anatomic basis of pure alexia. Neurology, 
33(12), 1573-1583.

Déjerine, J. (1892). Contribution à létude anatomo-pathologique et clinique des différentes variétés de cécité verbale. $C R$ Soc Biol 4, 61-90.

Déjerine, J. (1891). Sur un cas de c é cit é verbale avec agraohie, suivi d'autopsie. $C R$ Soc Biol 3, 197-201.

Exner, S. (1881). Untersuchungen über die Lokalisation der Funktionen in der Grosshirnrinde des Menschen. Wilhelm Braümuller, Wien.

Farah, M. J., \& Wallace, M. A. (1991). Pure alexia as a visual impairment: A reconsideration. CognitiveNeuropsychology, 8, 313-334.

Fushimi, T., Ijuin, M., Patterson, K., \& Tatsumi, I. (1999). Consistency, frequency, and lexicality effects in naming Japanese Kanji. Journal of Experimental Psychology: Human Perception and Performance, 25, 382-407.

Geschwind, N., \& Kaplan, E. (1962). A human cerebral deconnection syndrome: A preliminary report. Neurology, 12, 675-675.

Houghton, G., \& Zorzi, M. (2003). Normal and impaired spelling in connecitionist dual-route architecture. Cognitive Neuropsychology, 20(2), 115-162.

Iwata, M. (1984). Kanji versus Kana neuropsychological correlates of the Japanese writing system. Trends in Neurosciences, 7(8), 290-293.

Japan Society for Higher Brain Dysfunction Brain Function Test Committee (2003). Standard Language Test of Aphasia (SLTA), 2nd edition, Tokyo: Shinko Igaku Shuppan.

Japan Society for Higher Brain Dysfunction Brain Function Test Committee (2003). Visual Perception Test for Agnosia (VPTA), revised edition, Tokyo: Shinko Igaku Shuppan. Jochi university SALA project team (2004). Sophia Analysis of Language in 
Aphasia(SALA). Tokyo: Escor.

Jones, G. V. (1985). Deep dyslexia, imageability, and ease of predication. Brain and language 24(1), 1-19.

Kay, J., Lesser, R., \& Coltheart, M. (1992). Psycholinguistic Assessment of Language Processing in Aphasia (PALPA). London: Lawrence Erlbaum Associates.

Marshall, J. C., Newcombe, F. (1966). Syntactic and semantic errors in paralexia. Neuropsychologia 4, 169-176.

Marshall, J. C., Newcombe, F. (1973). Patterns of paralexia: A psycholinguistic approach. Journal of psycholinguistic research, 175-199.

McCarthy, R. A., \& Warrington, E. K. (1986). Phonological reading: Phenomena and paradoxes. Cortex 22, 359-380.

Miozzo, M., \& Caramazza, A. (1998). Varieties of pure alexia: The case of failure to access graphemic representations. Cognitive Neuropsychology, 15, 203-238.

Morton J, \& Sasanuma S. (1984). Lexical access in Japanese. In L. Henderson (Ed.), Orthographies and reading: Perspectives from cognitive psychology, neuropsychology, and linguistics (pp. 25-42). London: Lawrence Erlbaum Associates.

Patterson, K., \& Kay, J. (1982). Letter-by-letter reading: Psychological descriptions of a neurological syndrome. The Quarterly Journal of Experimental Psychology, 34(3), $411-441$.

Plaut, D. C., \& Shallice, T. (1993). Deep dyslexia. A case study of connectionist neuropsychology. Cognitive neuropsychology 10, 377-500.

Roeltgen, D. P. (2003). Agraphia. In K. M. Heilman \& E. Valenstein (Eds.), Clinical 
neuropsychology (4th ed., pp. 126-145). New York: Oxford University Press.

Roeltgen, D. P., \& Heilman, K. M. (1984). Lexical agraphia. Further support for the two-system hypothesis of linguistic agraphia. Brain, 107(3), 811-827.

Roeltgen, D. P., Sevush, S., \& Heilman, K. M. (1983): Phonological agraphia: writing by the lexical-semantic route. Neurology, 33(6), 755-65.

Sakurai, Y., Mimura, I., \& Mannen, T. (2008). Agraphia for kanji resulting from a left posterior middle temporal gyrus lesion. Behavioural Neurology 19, 93-106.

Sakurai, Y., Sakai, K., Sakuta, M., \& Iwata M. (1994), Naming difficulties in alexia with agraphia for kanji after a left posterior inferior temporal lesion, Journal of Neurology, Neurosurgery, and Psychiatry 57, 609-613.

Sakurai, Y., Mimura, I., \& Mannen, T. (2008). Agraphia for kanji resulting from a left posterior middle temporal gyrus lesion. Behavioural Neurology, 19, 93 -106.

Sakurai, Y., Sakai, K., Sakuta, M., \& Iwata, M. (1994). Naming difficulties in alexia with agraphia for kanji after a left posterior inferior temporal lesion. Journal of Neurology, Neurosurgery \& Psychiatry, 57, 609-613.

Sasanuma, S., Ito, H., Patterson, K., \& Ito, T. (1996). Phonological alexia in Japanese: A case study. Cognitive Neuropsychology, 13, 823-848.

Shallice, T. (1981). Phonological agraphia and the lexical route in writing. Brain 104, $413-429$.

Soma, Y., Sugishita, M., Kitamura, K., Maruyama, S., \& Imanaga, H., (1989) Lexical agraphia in the Japanese language. Pure agraphia for Kanji due to left posteroinferior temporal lesions, Brain 112 (1989), 1549-1561. 
Tainturier, M. J., \& Caramazza, A. (1994). The status of double letters in graphemic buffer impairment affecting nonword reading. Brain and Language, 47, 433-435.

Weekes, B., Davies, R., Parris, B. \& Robinson G., (2003). Age of acquisition effects on spelling in surface dysgraphia. Aphasiology, 17, 563-584.

Warrington, E. K., \& McCarthy, R. A. (1987). Categories of knowledge further fractionations and an attempted integration. Brain, 110, 1273-1296.

Warrington, E. K., \& Shallice, T. (1980). Word-form dyslexia. Brain, 103, 99-112. 


\section{Figure Legends}

Figure 1 Head computed tomography (CT)

A head CT scan acquired 2 days after manifestation revealed low-density areas in the left lower temporal lobe extending to the left occipital lobe, and a small infarction in the parietal lobe.

Figure 2 Percentages of correct answers on the reading and spelling tests

The patient spelled significantly fewer Kanji words correctly than Kana words $\left[\chi^{2}(1)=\right.$ 48.01, $\mathrm{p}<.01]$. His spelling scores were similar between Kana words and non-words. The Kana word spelling score was significantly higher than that of the Kana word reading score $\left[\chi^{2}(1)=80.12, \mathrm{p}<.01\right]$

Figure 3 Dual route cascaded (DRC) model of reading This model was modified from the original model (Coltheart et al. 2001) for Japanese reading.

Figure 4 Dual route cascaded (DRC) model of spelling

The DRC model of spelling was derived based on that of Houghton \& Zorzi (2003) and Weekes et al. (2003), and modified for Japanese spelling.

Table 1 Results of the Standard Language Test of Aphasia (SLTA)

The SLTA is the most commonly used standardized test battery for Japanese patients with aphasia.

Table 2 Comparison of our case with the case reported in Beauvois et al.

Both cases had an intact non-lexical route for spelling, while the reading lexical route was impaired only in our case. 


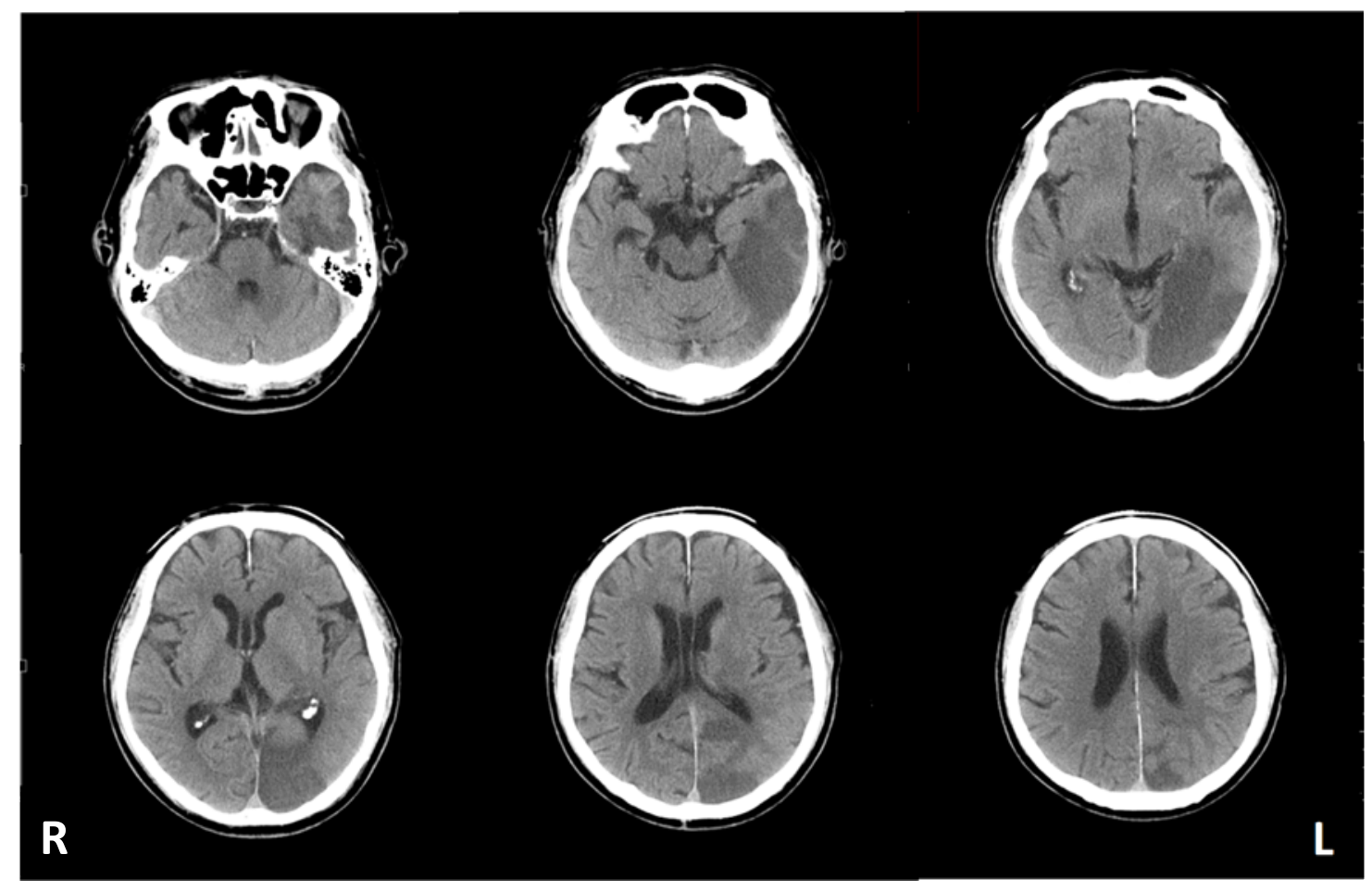

Figure 1 Head CT 


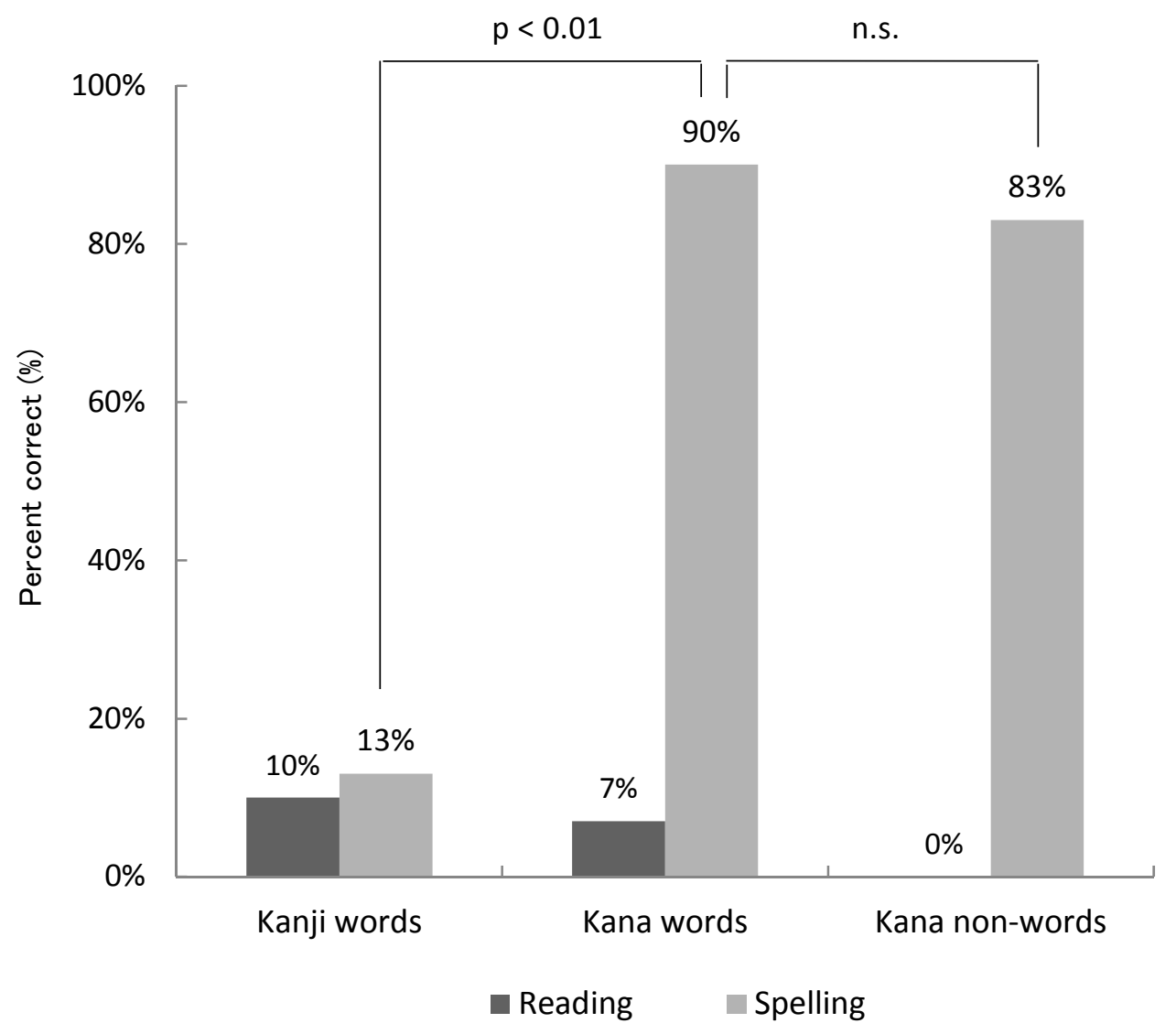

Figure 2 Percentage of correct answers on the reading and spelling tests 


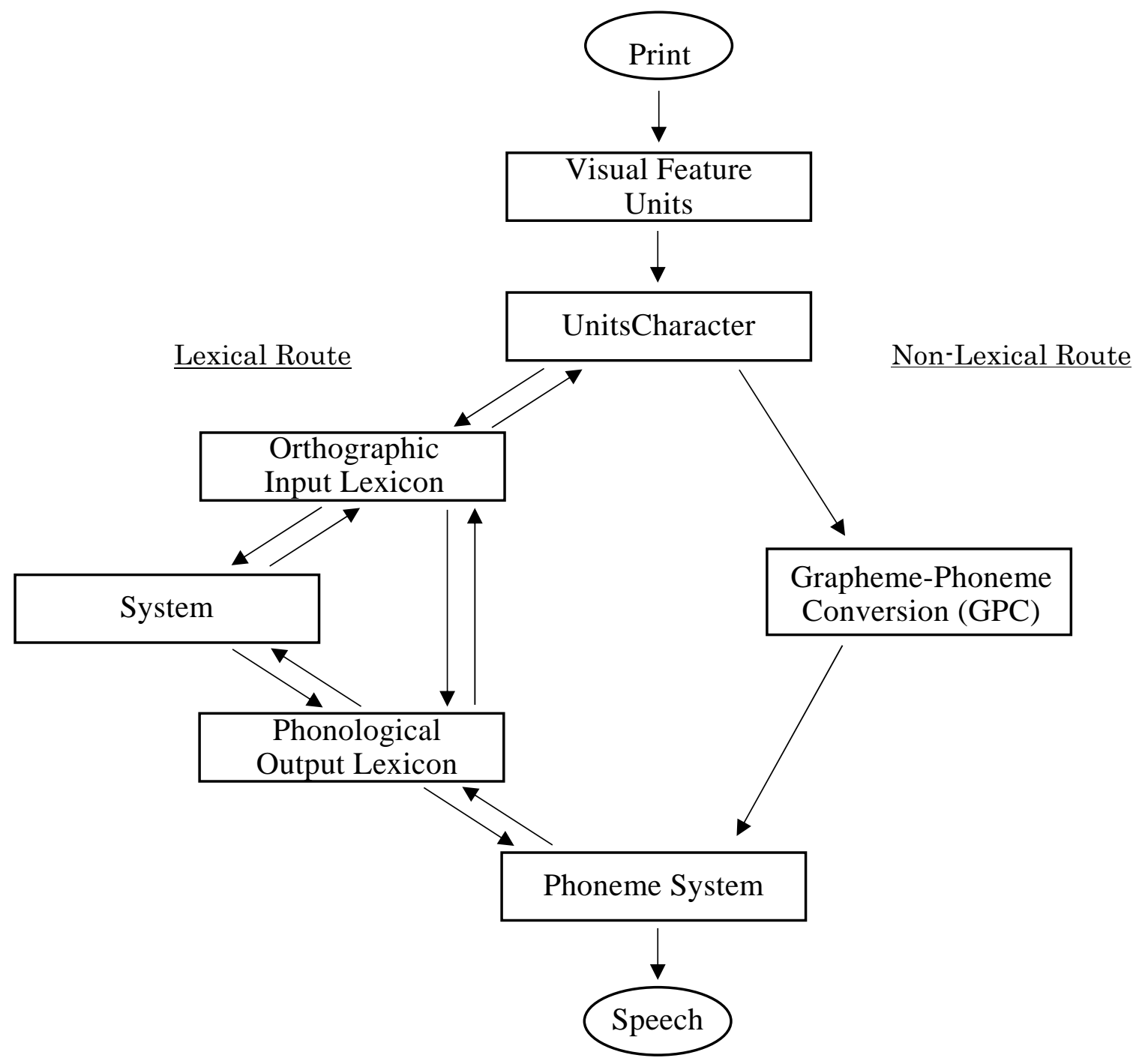

Figure 3 DRC model of reading 


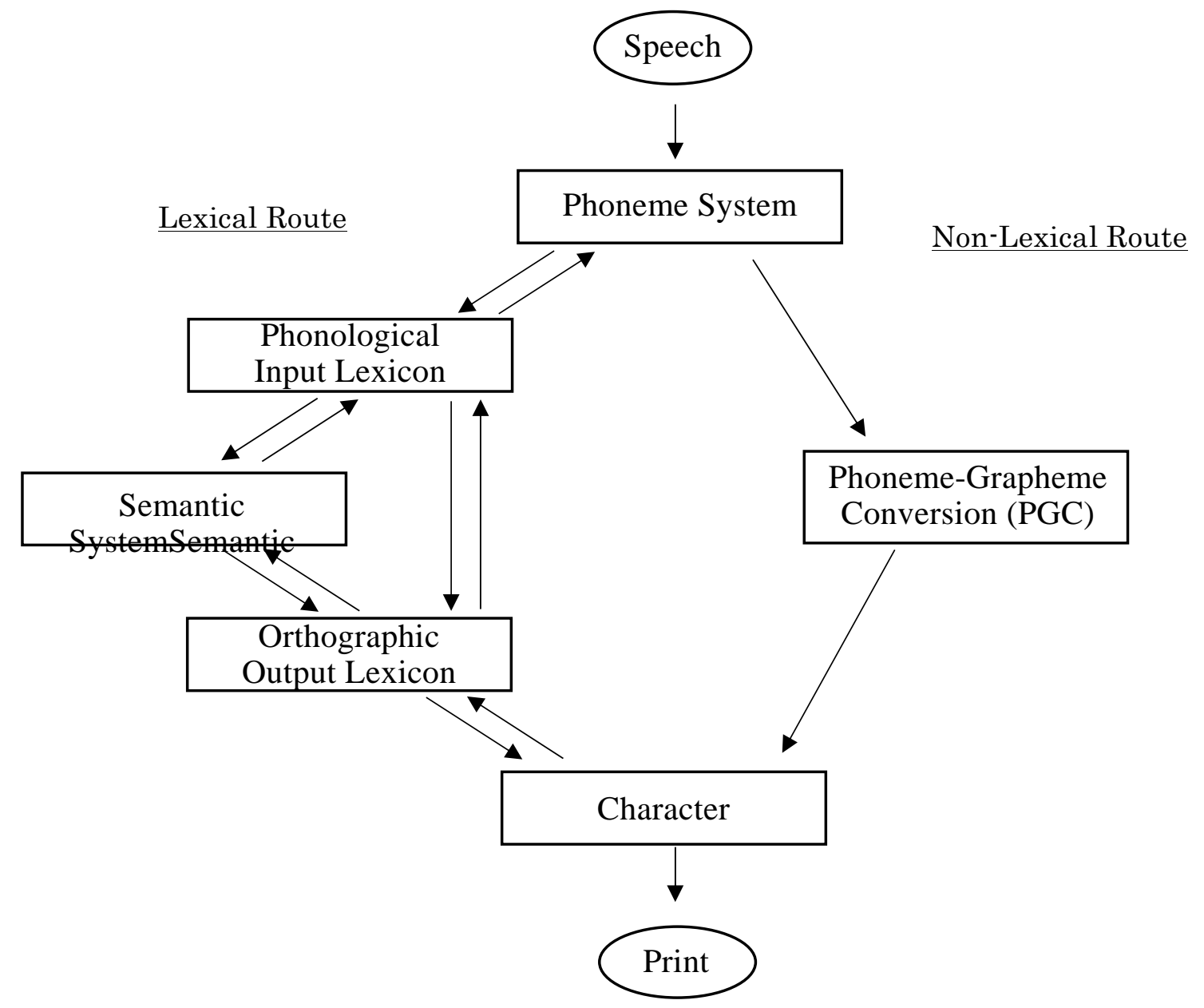

Figure 4 DRC model of spelling 
Table 1 Results of the Standard Language Test of Aphasia (SLTA)

\begin{tabular}{|c|c|c|c|c|}
\hline Task & Score & Max & Average & $\mathrm{SD}$ \\
\hline \multicolumn{5}{|l|}{ Comprehension } \\
\hline Spoken word-to-picture matching & 10 & 10 & 10.0 & 0.2 \\
\hline Spoken sentence comprehension & 9 & 10 & 9.5 & 0.8 \\
\hline Spoken command comprehension & $1^{\dagger}$ & 10 & 9.6 & 0.7 \\
\hline Kanji word-to-picture matching & $7^{\dagger}$ & 10 & 9.9 & 0.8 \\
\hline Kana word-to-picture matching & $3^{\dagger}$ & 10 & 10.0 & 0.1 \\
\hline Written sentence comprehension & $0^{\dagger}$ & 10 & 9.6 & 1 \\
\hline Written command comprehension & $0^{\dagger}$ & 10 & 9.4 & 1.5 \\
\hline \multicolumn{5}{|l|}{ Production } \\
\hline Oral naming: objects & $7^{\dagger}$ & 20 & 19.6 & 0.8 \\
\hline Oral naming: actions & $6^{\dagger}$ & 10 & 9.9 & 0.4 \\
\hline Oral scene description & 5 & 6 & 5.8 & 0.6 \\
\hline Word fluency & 9 & - & 12.6 & 4.5 \\
\hline Written naming of Kanji & $1^{\dagger}$ & 5 & 4.2 & 1.1 \\
\hline Written naming of Kana & 4 & 5 & 4.8 & 0.7 \\
\hline Written scene description & $1^{\dagger}$ & 6 & 5.2 & 1.1 \\
\hline \multicolumn{5}{|l|}{ Repetition } \\
\hline Words & 10 & 10 & 9.9 & 0.1 \\
\hline Sentences & 4 & 5 & 4.5 & 0.8 \\
\hline \multicolumn{5}{|l|}{ Reading aloud } \\
\hline Kanji words & $1^{\dagger}$ & 5 & 5.0 & 0.4 \\
\hline Kana words & $1^{\dagger}$ & 5 & 5.0 & 0.1 \\
\hline Kana characters & $0^{\dagger}$ & 10 & 10.0 & 0.2 \\
\hline Sentences & $0^{\dagger}$ & 5 & 4.9 & 0.3 \\
\hline \multicolumn{5}{|l|}{ Writing-to-dictation } \\
\hline Kanji words & $1^{\dagger}$ & 5 & 4.3 & 1.0 \\
\hline Kana words & 5 & 5 & 4.8 & 0.8 \\
\hline Kana characters & 9 & 10 & 9.7 & 1.1 \\
\hline Sentences & $1^{\dagger}$ & 5 & 4.0 & 1.5 \\
\hline
\end{tabular}


Table 2 Comparison of our case with the case of Beauvois et al.

\begin{tabular}{|c|c|c|c|c|}
\hline & \multicolumn{2}{|c|}{ Reading } & \multicolumn{2}{|c|}{ Spelling } \\
\hline & Lexical & Non-lexical & Lexical & Non-lexical \\
\hline Our case & $x$ & $x$ & $x$ & $\bigcirc$ \\
\hline Case of Beauvois et al. & $\bigcirc$ & $x$ & $x$ & 0 \\
\hline
\end{tabular}

